\title{
Sonographic Estimation of Visceral Adipose Tissue in an African Population
}

\author{
Thomas Adejoh ${ }^{*}$, Idigo Felicitas Ugochinyere ${ }^{2}$, Sobechukwu Warric Iwene Onwuzu ${ }^{3}$, \\ Nkubli Flavious Bobouin", Alhamdu Sila Moi4 \\ ${ }^{1}$ Radiology Department, Nnamdi Azikiwe University Teaching Hospital, Nnewi, Nigeria \\ ${ }^{2}$ Department of Medical Radiography and Radiological Sciences, University of Nigeria, Enugu Campus, Enugu, \\ Nigeria \\ ${ }^{3}$ Medical Imaging Unit, Department of Medical Center, University of Nigeria, Nsukka, Nigeria \\ ${ }^{4}$ Department of Medical Radiography, College of Medical Sciences, University of Maiduguri, Maiduguri, Nigeria \\ Email: adtoms@yahoo.com, vicugoo@yahoo.com, Sobechukwu.onwuzu@unn.edu.ng, \\ activeflavour@yahoo.com, moisolver@yahoo.com
}

Received 20 April 2015; accepted 25 May 2015; published 28 May 2015

Copyright (C) 2015 by authors and Scientific Research Publishing Inc.

This work is licensed under the Creative Commons Attribution International License (CC BY).

http://creativecommons.org/licenses/by/4.0/

(c) $\underset{\mathrm{EY}}{\mathrm{B}}$ Open Access

\begin{abstract}
Purpose: To establish normal values of sonographically-quantified visceral adipose tissue (VAT) in an African population and to correlate results with biomarkers. Patients and Methods: 100 male and 150 female volunteers were scanned for intra-abdominal adipose tissue thickness. Other parameters obtained include BMI, WC, and blood pressure (BP). Pearson correlation coefficient (r) was used to estimate the degree of relationship in VAT, BMI, WC, and blood pressure. Results: The mean VAT thickness was $25.36 \pm 16.42 \mathrm{~mm}$. VAT correlated positively and linearly with age $(\mathrm{r}=$ 0.651; $p<0.05$ ), BMI (males: $r=0.745$, $p<0.05$, and females: $r=0.736 ; p<0.05$ ), WC (males: $r=$ $0.797, p<0.05$; females: $r=0.779, p<0.05$ ), and systolic and diastolic blood pressure. (Systolic: $r=$ $0.524, p<0.05$, and diastolic: $r=0.535, p<0.05$ ). Conclusion: Ultrasound is a useful tool in assessing VAT during routine scans to identify patients at risk of increased blood pressure and cardiac diseases associated with obesity.
\end{abstract}

\section{Keywords}

Adipose Tissue, Blood Pressure, Viscera, Ultrasound

\section{Introduction}

Visceral adipose tissue (VAT) is a hormonally-active component of total body fat which possesses unique bio-

${ }^{*}$ Corresponding author.

How to cite this paper: Adejoh, T., Ugochinyere, I.F., Onwuzu, S.W.I., Bobouin, N.F. and Moi, A.S. (2015) Sonographic Estimation of Visceral Adipose Tissue in an African Population. Health, 7, 653-658.

http://dx.doi.org/10.4236/health.2015.75077 
chemical characteristics that influence several normal and pathological processes in the human body [1].

Intra-abdominal adipose tissue depot is made up of visceral intra-peritoneal fat and retro-peritoneal fat masses separated by a delineation along the dorsal margin of the intestine and the ventral surface of the kidney [2]. It is drained by the portal vein, whereas blood from retro-peritoneal adipose tissue empties into the inferior vena cava [3]. The anatomical distribution of adipose tissue throughout the human body is dependent upon many factors including sex, age, race, ethnicity, genotype, diet, physical activity, hormone levels and medication [1].

Excess VAT is a key contributor to abdominal obesity [4], which is believed to be a marker of dysfunctional adipose tissue [5]. Obesity further increases the risk of cardiovascular diseases in adults and has been strongly associated with insulin resistance in normoglycemic persons and in individuals with type 2 diabetes [6]. Quantitative assessment of visceral obesity is important for evaluating the potential risk of pathologies, as well as providing an accurate prognosis [1]. On ultrasound, the VAT is measured as the distance between the posterior border of the linea alba and the abdominal aorta (Figure 1) [4]. This study is aimed at creating a reference range normogram of the VAT, and correlating it with biometric markers like Body Mass Index (BMI), Waist Circumference (WC), and Blood Pressure (BP).

\section{Patients and Methods}

This was a prospective, cross sectional study carried out between December 2012 and March 2013 in a teaching hospital in Nigeria. 250 volunteers (100 males and 150 females) recruited consecutively through simple random sampling were enrolled for the study. They comprised outpatients for ultrasound with no sonographic evidence of abnormality, staff of the hospital as well as para-medical students on clinical attachment.

Ethical approval was obtained from the hospital's ethics committee and informed, written consent was also obtained from each subject. Excluded from the study were volunteers with previous history of abdominal surgery, gravid patients, medically-unfit patients, incidental findings of hepatic, pancreatic, or renal pathology, and those with dietary disorders.

The equipment used for visceral adipose tissue quantification was Aloka Prosound SSD-3500SX ultrasound machine with a sector transducer having a variable frequency range of 2.5 - $6 \mathrm{MHz}$. An aneroid sphygmomanometer and a stethoscope were used for blood pressure measurement. Waist circumference was assessed with the aid of a non-stretchable tape rule. A height and weight scale were also used.

The volunteer was positioned for a normal abdomino-pelvic ultrasound but with the head at the same level as the body. This head level neutralizes a likely sudden rise in blood pressure, seen sonographically as increased pulsation of the abdominal aorta, which often leads to difficulty in freezing.

The skin at the peri-umbilical area was exposed and ultrasound gel was applied. The transducer was positioned transversely at $1-5 \mathrm{~cm}$ superior to the umbilicus at the xipho-umbilical line. This position shows the rectus sheath as two contra-lateral, homogenous, fairly-oval, hypoechoic, solid structures separated by a central, homogenous and echogenic linea alba lying immediately superior to the pre-peritoneal fat which appears hypoe-

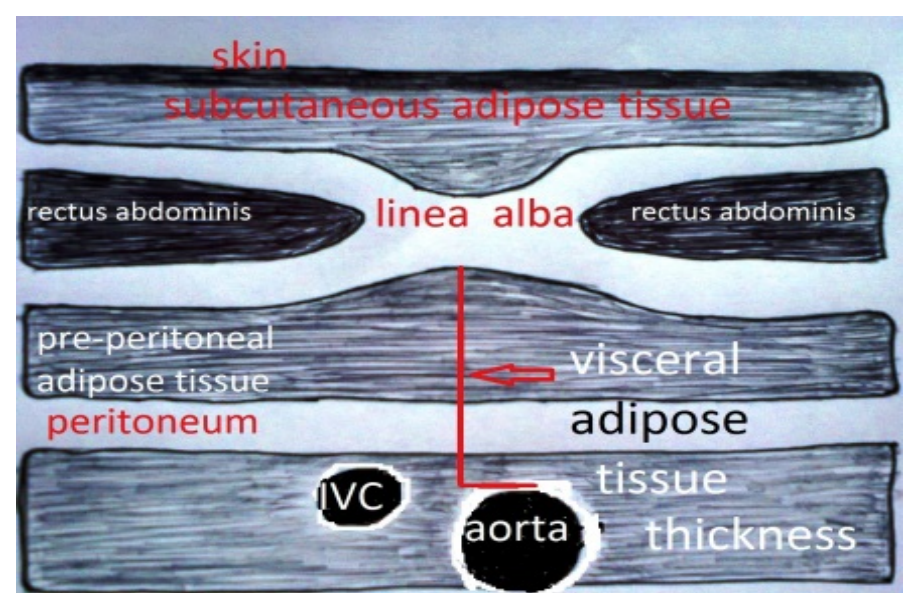

Figure 1. Schematic diagram of measurement reference point for visceral adipose tissue in transverse view. 
choic. Visceral adipose tissue appears echogenic, fairly homogenous and with bright linear cranio-caudal strips at regular interval. With the rectus sheath and linea alba sharply in focus on the screen, the transducer was subsequently rotated longitudinally and held stable at the median-sagittal plane with gentle hand pressure until the pulsating abdominal aorta came sharply into focus.

The electronic calipers were positioned between the anterior wall of the abdominal aorta and the posterior surface of the linea alba and the measurement was taken on arrested expiration. Two other measurements were obtained and the average of the three values represented the final VAT value (Figures 1-3).

The body mass index was calculated from weight and height measurements using the formula weight/height ${ }^{2}$ $\left(\mathrm{kg} / \mathrm{m}^{2}\right)$. Waist circumference was measured with the volunteer standing erect. Clothing were adjusted to reveal the umbilical segment. A flexible, non-stretchable tape rule was tied gently around the waist at the level of the umbilicus and held parallel to the floor. The measurement was taken on arrested expiration.

Blood pressure was measured by departmental nurses using aneroid sphygmomanometer and stethoscope. Volunteers were seated and measurements were taken consistently from the left arm after five minutes of rest. In all measurements the average of two readings were calculated and recorded.

The data obtained was analyzed using SPSS v.17.0 (SPSS Inc, Chicago, Illinois). Results were expressed as mean \pm standard deviation. The relationship between VAT and BMI, WC, and BP was determined by Pearson's correlation coefficient. A p-value $<0.05$ was considered as statistically significant.

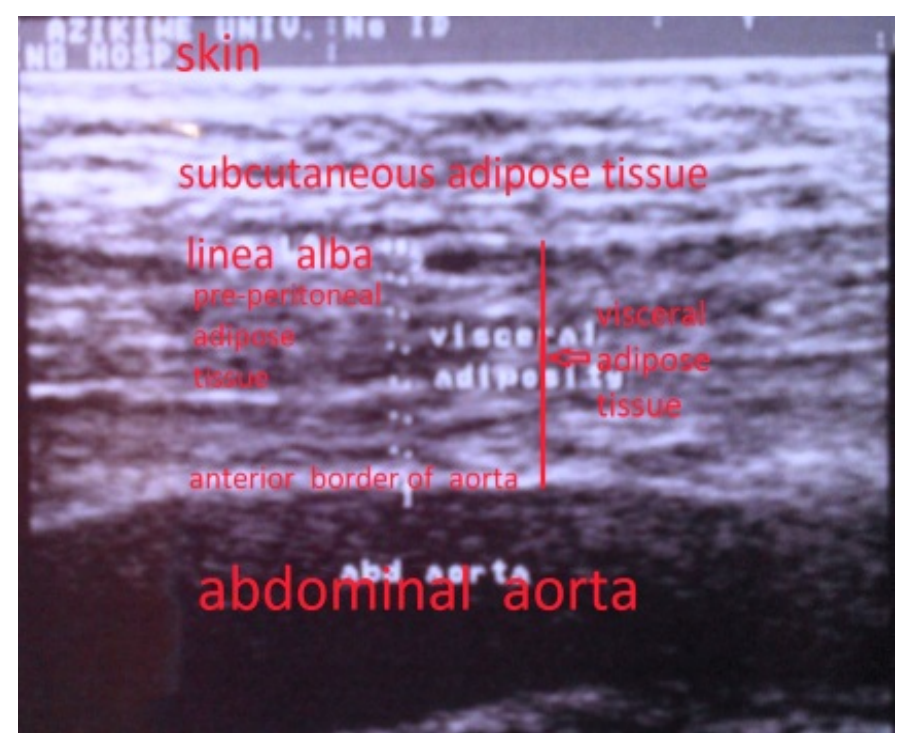

Figure 2. Sonogram of measurement landmarks in longitudinal view.

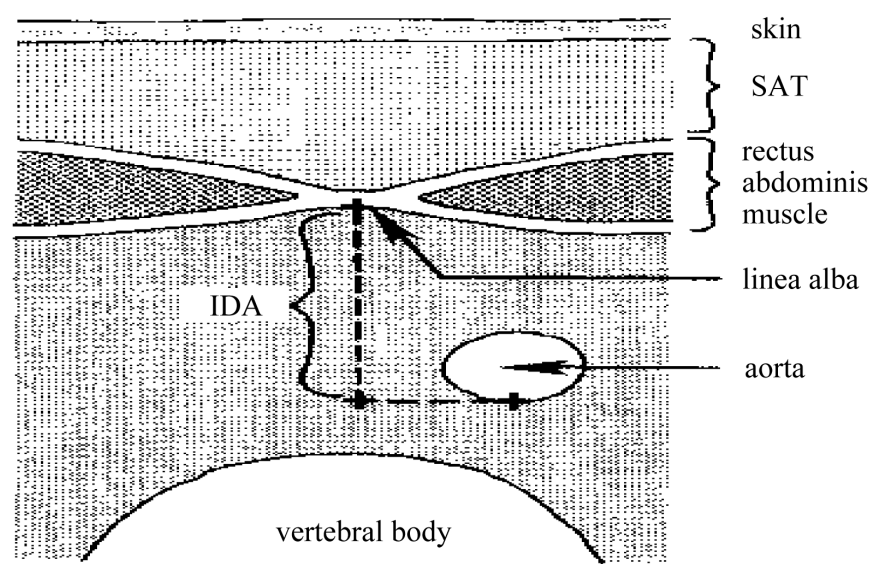

Figure 3. Measurement reference point for visceral adiposity in transverse view (c) Armellini et al., 1990. 


\section{Results}

250 volunteers (male:female ratio $=2: 3$ ) who were not on admission participated willingly in the study. 54\% (n $=135)$ were para-medical students, $40 \%(\mathrm{n}=100)$ were "normal" ultrasound patients and $6 \%(\mathrm{n}=15)$ were staff of the hospital (Table 1). Their age range was 18 - 65 years with a mean of $28.92 \pm 10.58$ years.

Minimum and maximum visceral adipose tissue thickness in the subjects were 10 and 105 mm respectively and with a mean of $25.36 \pm 16.42 \mathrm{~mm}$. In obese subjects $(\mathrm{n}=28)$ however, it was $45 \mathrm{~mm}, 105 \mathrm{~mm}$ and $73.0 \pm$ $14.0 \mathrm{~mm}$ respectively. Minimum, maximum and mean waist circumference in both male and female gender were $67 \mathrm{~cm}, 128 \mathrm{~cm}$ and $85.99 \pm 12.15 \mathrm{~cm}$ as well as $60 \mathrm{~cm}, 114 \mathrm{~cm}$ and $77.34 \pm 11.48 \mathrm{~cm}$ respectively. Both males and females had means lower than the cut off values for mild obesity of $94 \mathrm{~cm}$ and $80 \mathrm{~cm}$ respectively. Mean BMI was 25.54 \pm 4.53. Mean systolic and diastolic blood pressures were $117.01 \pm 11.04$ and $73.81 \pm 9.42$ mmHg respectively (Table 2).

Pearson's correlation revealed that VAT positively correlated with BMI, WC, and BP. While correlation was moderate in systolic $(r=0.601 ; p<0.05)$ and diastolic $(r=0.543$; $p<0.05)$ blood pressure in males it was low for both systolic $(r=0.302$; $p<0.05)$ and diastolic $(r=0.412$; $p<0.05)$ blood pressures in the female gender. The results are summarized in Table 2.

\section{Discussion}

Our findings strongly suggest that visceral adipose tissue can be reliably quantified with ultrasound. We also found positive and significant correlation of adipose tissue with biomarkers such as body mass index, waist circumference and blood pressure. A mean visceral adipose tissue thickness of $25.36 \pm 16.42$ mm was established for our Negroid population. In twenty-eight obese subjects with BMI $\geq 30 \mathrm{~kg} / \mathrm{m}^{2}$ however, we noted a mean

Table 1. Classification of volunteers.

\begin{tabular}{ccccc}
\hline & & Gender & Fetal (\%) \\
\cline { 2 - 4 } Volunteers & Male & 83 & $135(54 \%)$ \\
Students & 52 & 58 & $100(40 \%)$ \\
Patients & 42 & 9 & $15(6 \%)$ \\
Staff & 6 & $\mathbf{1 5 0}$ & $\mathbf{2 5 0}(\mathbf{1 0 0} \%)$ \\
Total & $\mathbf{1 0 0}$ & \\
\hline
\end{tabular}

Table 2. Dispersion and Pearson's correlation (r) of visceral adiposity with measured variables.

\begin{tabular}{|c|c|c|c|c|c|c|c|c|c|c|c|c|}
\hline \multirow{2}{*}{ Attributes } & \multicolumn{4}{|c|}{ All volunteers $(n=250)$} & \multicolumn{4}{|c|}{ Male volunteers $(\mathrm{n}=100)$} & \multicolumn{4}{|c|}{ Female volunteers $(n=150)$} \\
\hline & Min & Max & Mean \pm SD & $\mathrm{r}$ & Min & Max & Mean \pm SD & r & Min & Max & Mean \pm SD & $\mathrm{r}$ \\
\hline $\begin{array}{c}\text { Visceral adiposity in } \\
\text { study population (mm) }\end{array}$ & 10 & 105 & $\begin{array}{c}25.36 \pm \\
16.42\end{array}$ & & 10 & 105 & $\begin{array}{l}33.28 \pm \\
20.26\end{array}$ & & 10 & 62 & $\begin{array}{c}20.08 \pm \\
10.38\end{array}$ & \\
\hline $\begin{array}{c}\text { Visceral adiposity in } \\
\text { obese (BMI) population } \\
(\mathrm{mm}), \mathrm{n}=28\end{array}$ & 45 & 105 & $\begin{array}{c}73.0 \pm \\
14.0\end{array}$ & 0.358 & 45 & 105 & $72.0 \pm 19.0$ & 0.546 & 56 & 97 & $\begin{array}{c}73.0 \pm \\
11.0\end{array}$ & 0.274 \\
\hline Age (years) & 18 & 65 & $\begin{array}{c}28.92 \pm \\
10.58\end{array}$ & 0.651 & 18 & 65 & $\begin{array}{c}33.42 \pm \\
13.27\end{array}$ & 0.605 & 18 & 57 & $\begin{array}{l}25.92 \pm \\
6.89\end{array}$ & 0.574 \\
\hline Waist circumference $(\mathrm{cm})$ & 60 & 128 & $\begin{array}{c}80.80 \pm \\
12.47\end{array}$ & 0.786 & 67 & 128 & $\begin{array}{c}85.99 \pm \\
12.15\end{array}$ & 0.797 & 60 & 114 & $\begin{array}{c}77.34 \pm \\
11.48\end{array}$ & 0.779 \\
\hline Body mass index & 17.06 & 40.90 & $\begin{array}{l}25.54 \pm \\
4.53\end{array}$ & 0.677 & 19.49 & 40.90 & $25.17 \pm 4.30$ & 0.745 & 17.06 & 38.63 & $\begin{array}{c}24.12 \pm \\
4.65\end{array}$ & 0.736 \\
\hline Systolic BP (mmHg) & 85 & 155 & $\begin{array}{c}117.01 \pm \\
11.04\end{array}$ & 0.524 & 100 & 140 & $\begin{array}{c}122.61 \pm \\
9.42\end{array}$ & 0.601 & 85 & 155 & $\begin{array}{c}113.27 \pm \\
10.47\end{array}$ & 0.302 \\
\hline Diastolic BP (mmHg) & 50 & 100 & $\begin{array}{l}73.81 \pm \\
9.42\end{array}$ & 0.535 & 50 & 100 & $77.96 \pm 8.67$ & 0.543 & 50 & 100 & $\begin{array}{l}71.05 \pm \\
8.89\end{array}$ & 0.412 \\
\hline
\end{tabular}

$\mathrm{p}<0.05$ (2-tailed; significant). 
visceral adipose thickness of $73.0 \pm 14.0 \mathrm{~mm}$ (male: $72.0 \pm 19.0 \mathrm{~mm}$; female: $73.0 \pm 11.0 \mathrm{~mm}$ ).

In a closely related work amongst Caucasian subjects with ultrasound, a mean abdominal visceral adipose thickness of $98.0 \pm 25.0 \mathrm{~mm}$ in nineteen obese, bariatrics subjects with $\mathrm{BMI} \geq 32.9 \pm 3.7 \mathrm{~kg} / \mathrm{m}^{2}$ was established [7]. Race and ethnicity are noted to influence adiposity [1], hence the difference in mean adipose thickness between both works. This understanding informed our use of a homogenous population in our study. The lower pocket of adiposity noted in our study is suggestive of a lesser propensity for abdominal obesity amongst our population than in Caucasians.

The strong correlation of adiposity with BMI and WC observed by us gives a lot of hope about the reliability of ultrasound in this quantification technique as earlier reported from a review of the literature. From our study, adiposity found higher correlation in WC $(r=0.8)$ than in BMI $(r=0.677)$. This concurred with the work of Kunesova et al., who studied 216 women aged 17 to 67 years using several imaging methods including ultrasound, and got significant correlation of between ultrasound and WC $(r=0.89)$ [8]. This value is only slightly higher than the value we got in women $(\mathrm{r}=0.779)$ from our work. This indicates that WC is a better predictor of visceral adiposity than BMI. This conclusion is also in agreement with the thinking of Janssen et al. [9].

The remarkable correlation we noted in adiposity with both systolic $(r=0.524)$ and diastolic $(r=0.535)$ blood pressure gives some remote possibility of the association of adiposity with blood pressure. This line of thinking was reinforced in a work which found that individuals with high visceral adipose tissue had higher systolic and diastolic blood pressure values [10]. The likely implication is that ultrasound can be used to investigate the pre-disposing factor to hypertension by a simple quantification of visceral adipose tissue. Hypertensive individuals with lean mass may not have abdominal obesity as risk factor.

Our experience in this work reaffirms the thinking that ultrasound can be used to diagnose intra-abdominal obesity [11] if valid regression models are available. However, Shuster et al., expressed reservations as they are of the opinion that the techniques used in ultrasonography remain operator-dependent in quantitative measurements of body composition. He advocated proper precautions for operator protocols to promote consistent measures of visceral adiposity [1]. These pitfalls we endeavoured to avoid in our work by the consistency in volunteer's position, external and internal measurement landmarks, phase of respiration and hand pressure on probe (Figure 1 and Figure 2).

\section{Conclusion}

Adipose tissue quantification with ultrasound finds useful application in the field of bariatrics as adiposity not only is visible on the screen but also presents a distinct echogenicity from other abdominal organs. This makes differentiating lean from fat mass and subcutaneous from visceral adipose tissue in obese individuals possible [1]. Moreover, it could potentially be used to confirm cases of abdominal obesity established by anthropometric means prior to commencement of bariatric therapy. A paucity of literature on the subject matter was noted locally. We are therefore constrained to postulate that only few research works have been done on the subject matter in our locality. Our generated data (Table 2) may therefore be a starting point for future researchers.

\section{Limitation}

Male volunteers were not keen on a free abdomino-pelvic ultrasound scan giving rise to a fairly wide margin of male:female ratio (2:3) in this work. Furthermore, a paucity of literature in the locality limited us from making appropriate comparisons in adipose tissue thickness between different negroid populations.

\section{Recommendation}

Further estimation of subcutaneous, pre-peritoneal and visceral adipose tissue with ultrasound amongst other Negroid populations in Nigeria to establish baseline estimates is recommended.

\section{References}

[1] Shuster, A., Patias, M., Pinthus, J.H. and Mourtzakis, M. (2012) The Clinical Importance of Visceral Adiposity: A Critical Review of Methods for Visceral Adipose Tissue Analysis. British Journal of Radiology, 85, 1-10. http://dx.doi.org/10.1259/bjr/38447238

[2] Tarantino, G., Lobello, R., Scopacasa, F., Contaldo, F., Pasanisi, F., Cirillo, M., et al. (2007) The Contribution of 
Omental Adipose Tissue to Adipokine Concentrations in Patients with the Metabolic Syndrome. Clinical \& Investigative Medicine, 30, E192-E199.

[3] Shen, W., Wang, Z.M. and Heymsfield, S.B. (2003) Adipose Tissue Quantification by Imaging Methods: A Proposed Classification. Obesity Research, 11, 5-16. http://dx.doi.org/10.1038/oby.2003.3

[4] Jung, C.-H., Kim, B.-Y., Kim, K.-J., Jung, S.-H., Kim, C.-H., Kang, S.-K. and Mok, J.-O. (2014) Contribution of Subcutaneous Abdominal Fat on Ultrasonography to Carotid Atherosclerosis in Patients with Type 2 Diabetes Mellitus. Cardiovascular Diabetology, 13, 67. http://dx.doi.org/10.1186/1475-2840-13-67

[5] Després, J.P. and Lemieux, I. (2006) Abdominal Obesity and Metabolic Syndrome. Nature, 444, 881-887. http://dx.doi.org/10.1038/nature05488

[6] Steinberger, J. and Daniels, S.R. (2003) Obesity, Insulin Resistance, Diabetes, and Cardiovascular Risk in Children. Circulation, 107, 1448-1453. http://dx.doi.org/10.1161/01.CIR.0000060923.07573.F2

[7] Stolk, R.P., Wink, O., Zelissen, P.M.J., Meijer, R., van Gils, A.P.G. and Grobbee, D.E. (2001) Validity and Reproducibility of Ultrasonography for the Measurement of Intra-Abdominal Adipose Tissue. International Journal of Obesity, 25, 1346-1351. http://dx.doi.org/10.1038/sj.ijo.0801734

[8] Kunesová, M., Hainer, V., Hergetová, H., Zák, A., Parízková, J., Horejs, J. and Stich, V. (1995) Simple Anthropometric Measurements-Relation to Body Fat Mass, Visceral Adipose Tissue and Risk Factors of Atherogenesis. Sb Lek, 96, 257-267.

[9] Janssen, I., Katzmarzyk, P.T. and Ross, R. (2004) Waist Circumference and Not Body Mass Index Explains ObesityRelated Health Risk. American Journal of Clinical Nutrition, 79, 379-384.

[10] Stolk, R.P., Meijer, R., Mali, W.P.T.M., Grobbee, D.E. and Graaf, Y. (2003) Ultrasound Measurements of Intraabdominal Fat Estimate the Metabolic Syndrome Better than Do Measurements of Waist Circumference. American Journal of Clinical Nutrition, 77, 857-860.

[11] Rhéaume, C., Arsenault, B.J., Bélanger, S., Pérusse, L., Tremblay, A., Bouchard, C., Poirier, P. and Després, J.P. (2009) Low Cardiorespiratory Fitness Levels and Elevated Blood Pressure: What Is the Contribution of Visceral Adiposity? Hypertension, 54, 91-97. http://dx.doi.org/10.1161/HYPERTENSIONAHA.109.131656 